\title{
Design of control system based on D-H method for live-maintain robot on Energized Transmission
}

\author{
J.J. Zhang, X.Q. Liu, J. Niu \& D.H. Zou \\ Hunan Provincial Live Working Center of State Grid, Changsha, China \\ Q.W. Pan \\ Changsha University of Science and Technology, Changsha, China \\ X.Q. Xiao \\ State Grid Hunan Maintenance Company, China
}

\begin{abstract}
On the foundation of a kinematics modeling based on D-H method, in this paper, we designed the control system of live-maintain robot on energized transmission. After analysis requirements of practical and control of robot, the control system is designed by being integrated, which is good to coordinate sport joints. The control system of robot is made up by sport control system, video system, power supply system and communication system. The wireless and 3G network card constitute the base station system. The result of test on high voltage laboratory and practical energized transmission further proved the stability of control system, the ability of anti- electromagnetic interference and transmission of information and the practicability of the robot.
\end{abstract}

KEYWORDS: D-H method; control system; live-maintain robot; Energized Transmission

\section{INTRODUCTION}

Live line work for transmission lines is one of the important way to ensure power supply reliability (Hu, Y. 2006) (Hu, Y. 2004). At present, live operator mostly used live working tools directly or indirectly to finished power system transmission line maintenance, however, when working on the compact line towers or loop line tower line, due to space distance is too small, Maintenance personnel will face great potential dangers, so it is eager to Study of a live-maintain robot instead of Operation personnel to charge operating personnel job (Pouliot, N. et al, 2008).

At present, many countries has carried out the research of automated mechanical device, Kyushu Electric Power Company has proposed a technology which can make full use of virtual reality technology, sensor technology, laser technology, image processing, pattern recognition, computer communication and data processing ability to structure Comprehensive friendly man-machine platform, this idea is Intended to the direction of the Full automatic intelligent operation, but the autonomous robot development still need some days $^{[4]}$; University of Manitoba in Canada has developed a hydraulic mechanical manipulator which can remotely control by operating personnel, carrying terminal device for dismantle and install Insulator, Manual operation virtual fixture, and Sending Information instructions about tasks in the work area to Controlled Terminal device, but the robot give first place to distribution network line maintenance (Montambault, S. 2007); Whatever at home and abroad, It is rare to see research of live-maintain robot on $110 \mathrm{kV}$ and above high voltage transmission line, at abroad, Quebec Hydropower Research Institute of Canada is typical, domestic typical have Wuhan University, Shandong Electric Power Research Institute, which still need to improving in some place (BAI,Y.C. 2005) (Mao, J.G. 2012) (WANG, C.D. 2013) (XU,X.J. 2011) (Zheng. 2012). Based on the good research and development work at home and abroad, the project team has carried out the research on the key technology of the $110 \mathrm{kV}-220 \mathrm{kV}$ high voltage transmission line maintenance robot, and successfully developed the prototype.

The stability and complete of Control system determine the stability, practicality and intelligence of the robot (ZHANG, H.W. 2006). On the foundation of a kinematics modeling based on D-H method, designed a robot control system with PC104 industrial control computer as the core with the idea of software modularization (Zhang, M. 2015). The control system is mainly include sport control system, video system, power supply system, communication system, Ground base station and so on. It also can analyzed the performance of the control system and field trial. 
2 ANAYLSIS OF LIVE LINE WORK FOR TRANSMISSION LINES TASK AND MECHANISM CONFIGURATION SCHEME

The feature that Smaller space distance of $110 \sim 220$ $\mathrm{kV}$ transmission lines (especially the multi-lines on a single tower) bring some security risks to operating personnel, This problem is particularly prominent when operating personnel used equal potential method to replace Insulator which Connected with bowl hanging plate, because of that, It is very urgent to use the robot to replace or assist the operation personnel to carry on the demand of the insulator operation project. In this paper, the research of live-maintain robot Can replace equal potential workers finished some work such as removing and installing Insulator which Connected with bowl hanging plate, realizing replacing carious strain insulators With the cooperation of worker who on the corss arm.

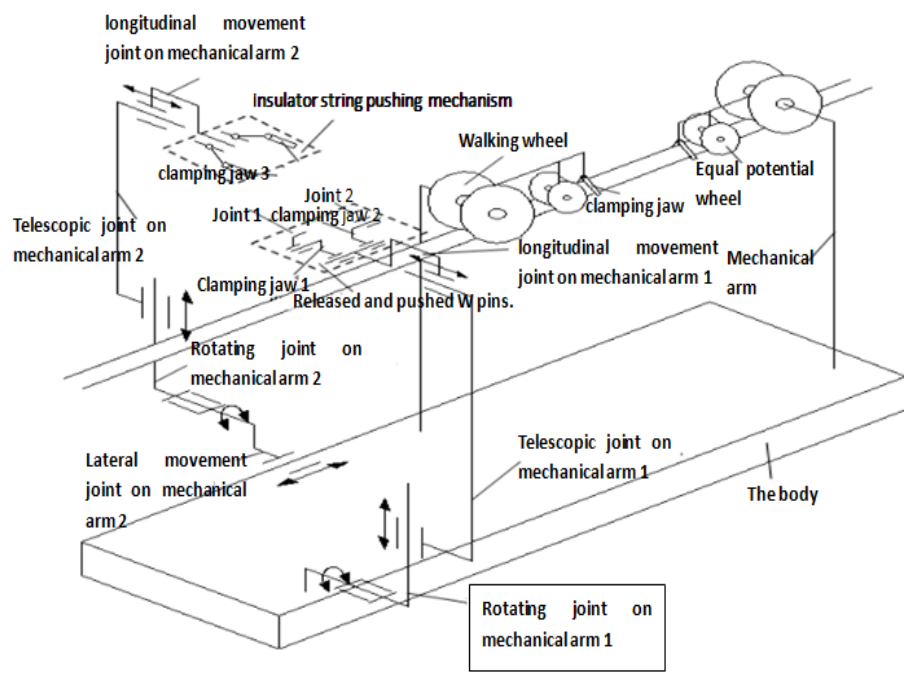

Figure 1. Structure of live-maintain robot on Energized Transmission

According to the $\mathrm{D}-\mathrm{H}$ kinematic modeling in literature, we design of live-maintain robot on Energized Transmission which is shown in figure 1.Live-maintain robot taking the mobile robot which is mainly constitute by Body, mechanical arm, walking wheel mechanism, clamping jaw, and other potential wheels, two robotic arm in the middle of the body's anti-symmetric arrangement with a fixed distance, walking wheel mechanism connected with the robot arm, work-holding devices which can clamp the wire along the walking wheel is used to protect the jaw line. According to principle of equal potential operation, a potential wheel is arranged at the side of the work-holding devices to ensure that the robot is always keep potential as the same as the wire. Two mechanical arm were carrying a robot arm, located on both sides of the body, respectively, for 3-DOF, 4-DOF mechanism, the rotating joint 1 and the rotating joint 2 can be rotated in a vertical plane, and the 1 and the 2 of telescopic joint can drive the end actuator mechanism to realize the vertical direction lifting; The longitudinal moving joint 1 can adjust the position of the middle surface of the end actuator mechanism to the center of the bowl, The longitudinal moving joint 2 can adjust the position of the middle surface of the end actuator mechanism to the center of the insulator string. The manipulator 1 is fixed on the machine body, and the manipulator 2 has a Lateral movement joint 2 which can be moved along the horizontal body. Each joint will bring or depart the end actuator mechanism to the work plane, the end actuator mechanism is constituted by $\mathrm{W}$ pin pushing mechanism and insulator string pushing mechanism. The $\mathrm{W}$ pin device is composed of three lateral movement joints, a movable joint carrying jaw 1, 2 which realize the clamping of the bowl hanging plate, and the other two movable joints are respectively released and pushed $\mathrm{W}$ pins. The mechanism with function of fetch and install Insulator strings can used the clamping jaw to Clamp steel cap.

\section{THE OVERALL DESIGN OF CONTROL SYSTEM OF LIVE-MAINTAIN ROBOT}

On the basis of detailed analysis of the functional requirements, combined with the power and control requirements of the robot, the integrated design of the control system is carried out and the following technical routes are proposed:

1) The system needs to control a lot of the number of motor and It must cause complex system structure and large energy consumption In order to improve the efficiency of the motor, the motor needs to realize the linkage control. In order to reduce the energy consumption and weight of the control system, in this system, adopting Packet switching mode to realize time-sharing control of multiple motors In order to achieve the balance between system efficiency and structure, energy consumption.

2) Walking wheel speed control accuracy requirements are relatively high, need real-time speed control to prevent slipping. Therefore, walking wheel motor to take control of better performance of the DC brush motor, and a pulse encoder is mounted at the end part of the motor, to accurate, real-time detection speed feedback. Walking wheel is require for high accuracy of speed control and the speed should be real-time control to prevent slipping, therefore, walking wheel motor adopts DC brush motor with good control performance, and a pulse encoder is installed at the end of the motor in order to timely and accurate testing rate feedback. 
3) In order to realize the recognition of the environment, the robot needs to process the Peripheral sensor information. To this end, Multi function acquisition card is used for real-time detection of the robot's internal and external sensor and the collected information is comprehensively processed by the PC104 industrial control computer.

4) The collection of video information is realized by the video server.

5) The power supply of the system is realized by an independent power control board In order to realize the integrated management control of the system power supply.

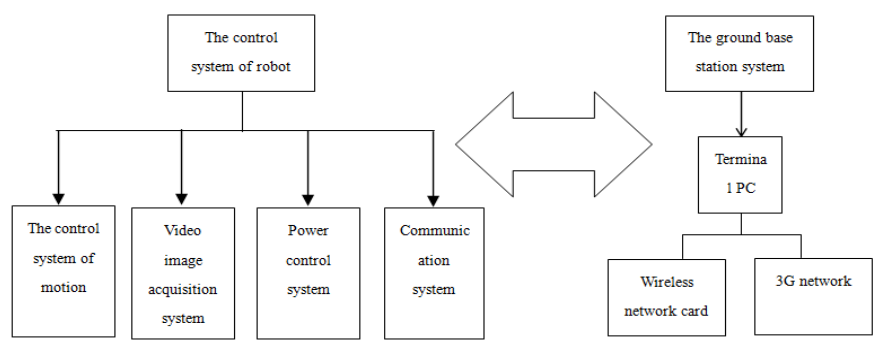

Figure 2. Structure of overall control system of live-maintain robot

The design of the control system of the live-maintain robot is shown in Figure 2. The system is mainly composed of two main systems, control system and ground base station system, the main control system is mainly composed of four parts, which are motion control system, video capture system, power control system and communication system. The ground base station system is mainly composed of PC machine equipped with Wireless LAN card and 3G modem. The control system and the ground base station system are mainly connected by the communication system.

\subsection{Design of control system}

The design of the control system is shown in Figure 3 , the core of the movement control system is PC104 computer which can obtain the motion state of the robot manipulator by the Information of the sensor such as position sensor and the inclination angle sensor and so on, and then control the action of the motor. The robot arm has 17 motors and 6 Elmo motor drives, the two walking wheels are driven separately by a driver, the other 15 motors share 4 drives and the control is carried out by closed loop transform, and the motor function is shown in table 1. The function of video capture system is capture the video image at Job Site through 4-way mini camera and Video server on the robot body then Transfer the information to ground base station by Ethernet, So that users can make the corresponding control decisions when control the robot. The power management system is used to unified and effective management of power allocation for robots to ensure the power supply of the system is controlled and reset operation. The power control module using ARM chip as the main controller, In addition, the ARM chip is also responsible for collecting the information of voltage detection, detection of the current in main circuit, obliquity sensor, Warm Humidity Sensor. Communication system is mainly responsible for the communication between the robot's electrical system components and the ground base station. The cable is used to communication inside the robot, Wifi is used to communication outside the robot.

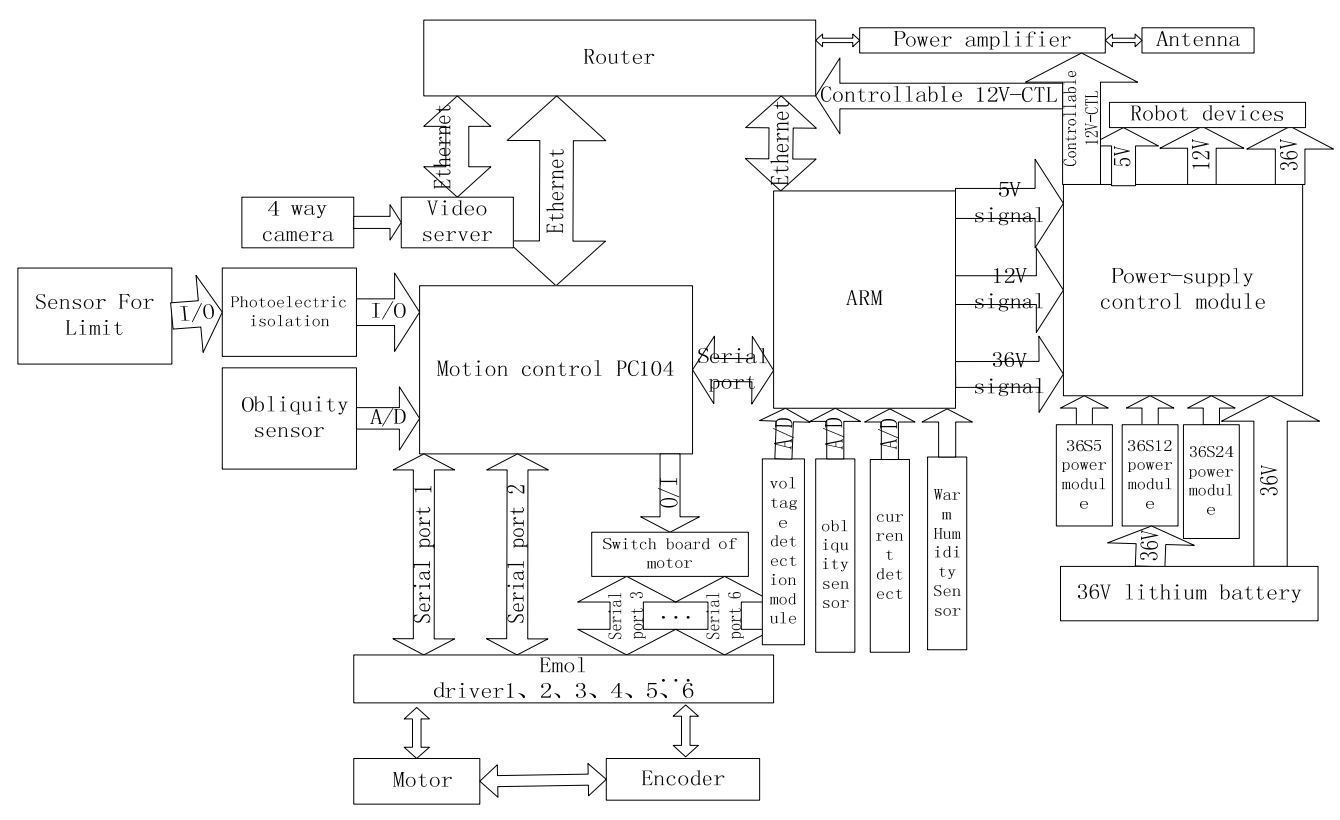

Figure 3. Structure of control system of live-maintain robot 


\subsubsection{Design of motion control system}

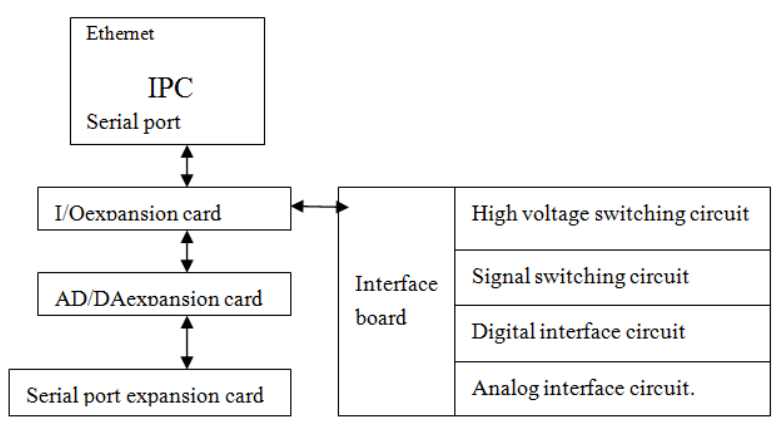

Figure 4. Structure of control system about movement

Table 1. Function of motors of live-maintain robot

\begin{tabular}{|c|c|c|}
\hline number & name of motor & Remark \\
\hline 1 & $\begin{array}{l}\text { Motor for walking wheel on } \\
\text { the mechanical arm } 1\end{array}$ & \multirow{11}{*}{$\begin{array}{l}\text { Common } \\
\text { motor }\end{array}$} \\
\hline 2 & $\begin{array}{l}\text { Motor for walking wheel on } \\
\text { the mechanical arm } 2\end{array}$ & \\
\hline 3 & $\begin{array}{l}\text { Motor for Clamping on the } \\
\text { mechanical arm } 1\end{array}$ & \\
\hline 4 & $\begin{array}{l}\text { Motor for Clamping on the } \\
\text { mechanical arm } 2\end{array}$ & \\
\hline 5 & $\begin{array}{l}\text { Motor on the rotating joint } \\
\text { of robot arm } 1\end{array}$ & \\
\hline 6 & $\begin{array}{l}\text { Motor on the rotating joint } \\
\text { of robot arm } 2\end{array}$ & \\
\hline 7 & $\begin{array}{l}\text { Motor for telescopic on the } \\
\text { mechanical arm } 1\end{array}$ & \\
\hline 8 & $\begin{array}{l}\text { Motor for telescopic on the } \\
\text { mechanical arm } 2\end{array}$ & \\
\hline 9 & $\begin{array}{l}\text { Motor for Vertical } \\
\text { movement on the } \\
\text { mechanical arm } 1\end{array}$ & \\
\hline 10 & $\begin{array}{l}\text { Motor for Vertical } \\
\text { movement on the } \\
\text { mechanical arm } 2\end{array}$ & \\
\hline 11 & $\begin{array}{l}\text { Motor for Lateral movement } \\
\text { on the mechanical arm } 2\end{array}$ & \\
\hline 12 & $\begin{array}{l}\text { Motor for clamping of the } \\
\text { bowl hanging plate }\end{array}$ & \multirow{4}{*}{$\begin{array}{l}\text { Special motor } \\
\text { for fetching } \\
\text { and loading } \\
\text { insulator }\end{array}$} \\
\hline 13 & Motor for Released W pins & \\
\hline 14 & Motor for pushed W pins & \\
\hline 15 & $\begin{array}{l}\text { Motor for clamping } \\
\text { insulator strings }\end{array}$ & \\
\hline 16 & Motor for clamping bolt & $\begin{array}{l}\text { Special motor } \\
\text { for clamping } \\
\text { and screwing } \\
\text { bolt }\end{array}$ \\
\hline
\end{tabular}

The structure of motion control system is shown in Figure 4, including IPC, IO expansion card, AD/DA expansion card, serial-port extender card, interface board and other parts. IPC is responsible for the collection of information through the expansion board, then the expansion board processing the result of information to control motor operation. The interface board is responsible for the collection and redistribution of the information of the expansion board, Specifically, Collecting robot sensor information and controlling motor switch by electrical connections between high voltage switching circuit, Signal switching circuit and Digital and analog interface circuit.

\subsubsection{Design of video capture system}

Video capture system as shown in Figure 5, the main part of the system is video server and interface board. The video server is mainly responsible for capture the video image at Job Site, and the interface board is responsible for the distribution of the image signal and the distribution of the interface. The video server collects the video image information of the four-way video camera, and Transfer the information to the ground base station by wireless router.

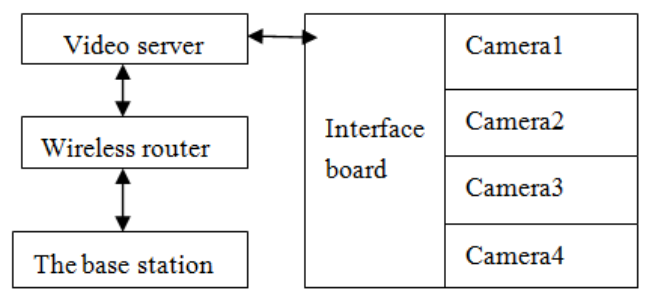

Figure 5. Structure of control system about video

\subsubsection{Design of power management system}

The power management system is shown in Figure 6 , it is used to unified and effective management of power allocation for robots to ensure the power supply of the system is controlled and reset operation.

The core component of the system is choose STM32F407VCT6 as ARM control chip, which can receive the instructions from the ground base station and detect the voltage of the robot cell then feedback the voltage value of the robot to the ground station. The operating power supply voltage level is $+5 \mathrm{~V}$, $+12 \mathrm{~V},+24 \mathrm{~V},+36 \mathrm{~V}$, the power supply is controlled by the electronic switch circuit and the single chip can realize the control of the power system of the robot and the operation of the power on reset by Control electronic switch circuit. Because of the robot is operating in the high-voltage wire, for the sake of the safety of robot and the wire, , the robot's battery voltage is very important, so the system set up a module which can monitor battery voltage . Due to the system of the battery voltage is $36 \mathrm{~V}$ but the working voltage of the STM32F407VCT6 port is $0-5 \mathrm{~V}$, so we design the amplifier circuit which can reduced 11 times of the battery voltage to let STM32F407VCT6 can read the value of battery voltage reduction, then transmitting the read value to 
Robot base station through the Serial communication, so that the operator can Easily read battery voltage value.

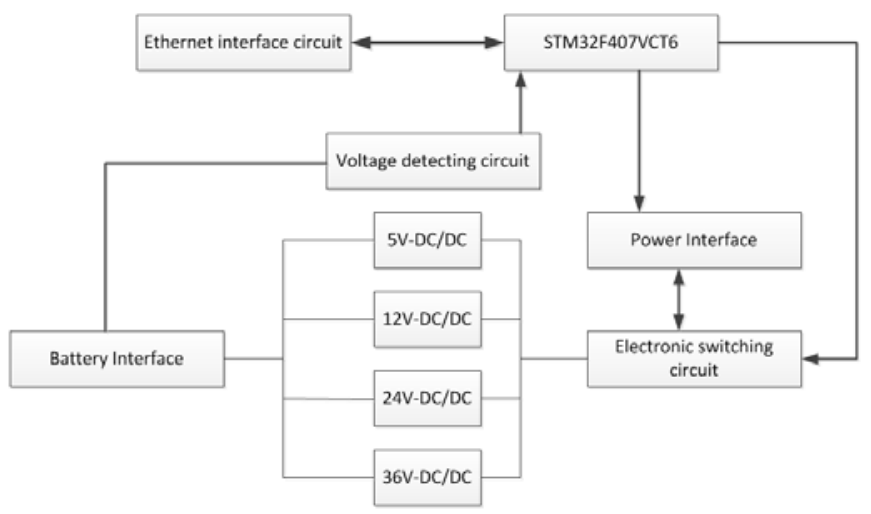

Figure 6. Structure of control system about power supply

\subsubsection{Design of communication system}

The structure of the communication system is shown in Figure 7.IPC, Video server and ARM chip connected to a wireless router through Cable, the wireless router establishes the communication connection with the ground base station with the wireless network card through WIFI, so that can realized real-time communication between Robot and ground base station. WiFi as a communication tool between the robot body and the base station, Contains a wireless router, signal amplifier etc, The wireless router is the core components for established communication of each system which make the system have the function of WLAN communication, The signal amplifier is used to amplify the wireless signal of the router in order to extend the communication distance between the robot and the ground base station.

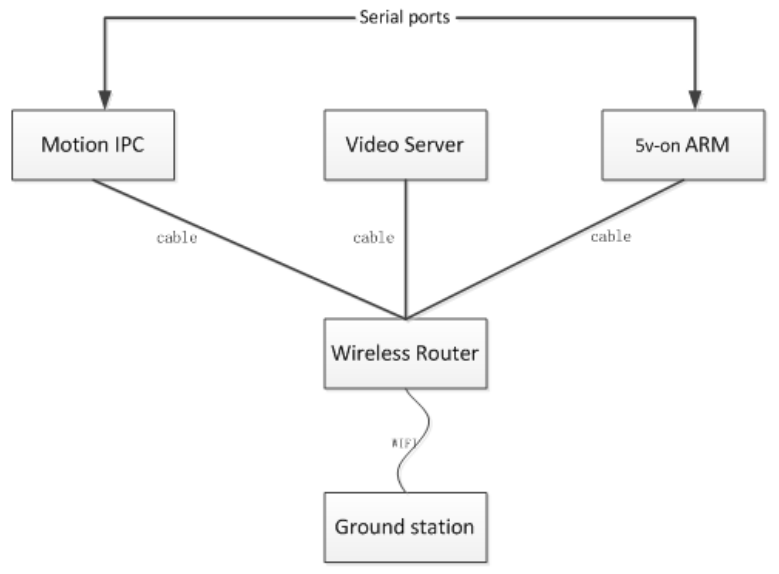

Figure 7. Structure of control system about communication

The device used for establishing the WLAN includes a wireless network card, a local area network based on the wireless router, etc. This project developed live-maintain robot for work on single span and the non blocking communication distance between the robot and the ground base station is not large, so WIFI can meet the communication requirements. However, considering the further development of the robot with function of obstacle crossing on Multi-span and the non blocking communication distance between the robot, the ground base station is increasing with the increase of the operating range so that it is difficult to meet the requirements of long distance communication by using the equipment directly. Therefore, extending the distance of wireless communication is a key technology to realize the communication of live-maintain robot.

\subsection{Design of ground base station}

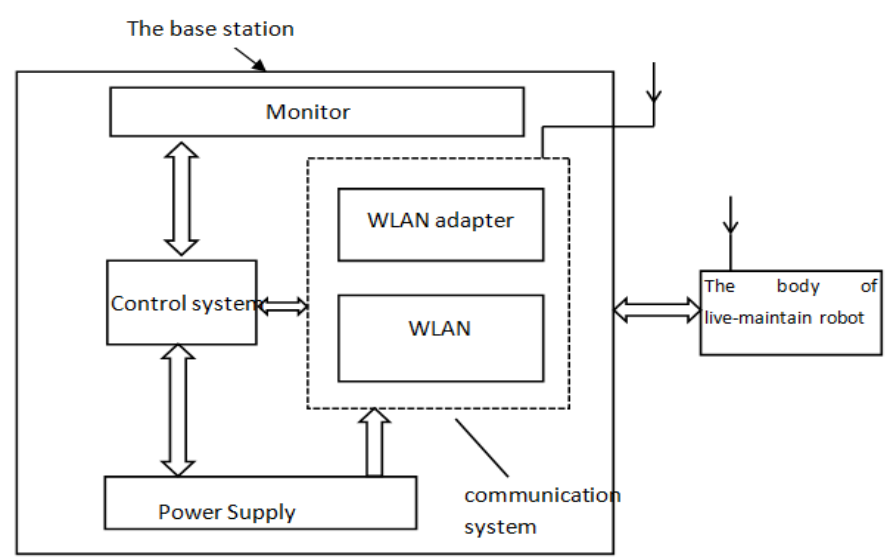

Figure 8. Structure of the base station system

Structure of the base station system and its connection with the robot as shown in figure 8, base station system is contains a wireless network card and PC which can realize WiFi communication, the base station Wireless Remote Control of the robot by WLAN or WiFi, at the same time, the state information of the robot can also be transferred to the ground base station through WiFi.

\section{DESIGN OF HARDWARE PLATFORM OF CONTROL SYSTEM}

\subsection{Sensor Layout Planning}

The live-maintain robot contains a variety of sensors, such as, Limit sensor for release is installed in the mechanical arm 1 and mechanical arm 2, Limit sensor for rotation is installed in the mechanical arm 1 and mechanical arm 2, Limit sensor for telescopic is installed in the mechanical arm 1 and mechanical arm 2, Limit sensor for longitudinal movement is installed in the mechanical arm 1 and mechanical arm 2, Limit sensor for lateral 
movement is installed in the mechanical arm 2, Limit sensor for release is installed in the insulator string clamping mechanism, Limit sensor for movement is installed in the $\mathrm{W}$ pin, Limit sensor for movement is installed in the Bowl head hanging plate clamping mechanism. The layout of these sensors on the robot is shown in Figure 9.

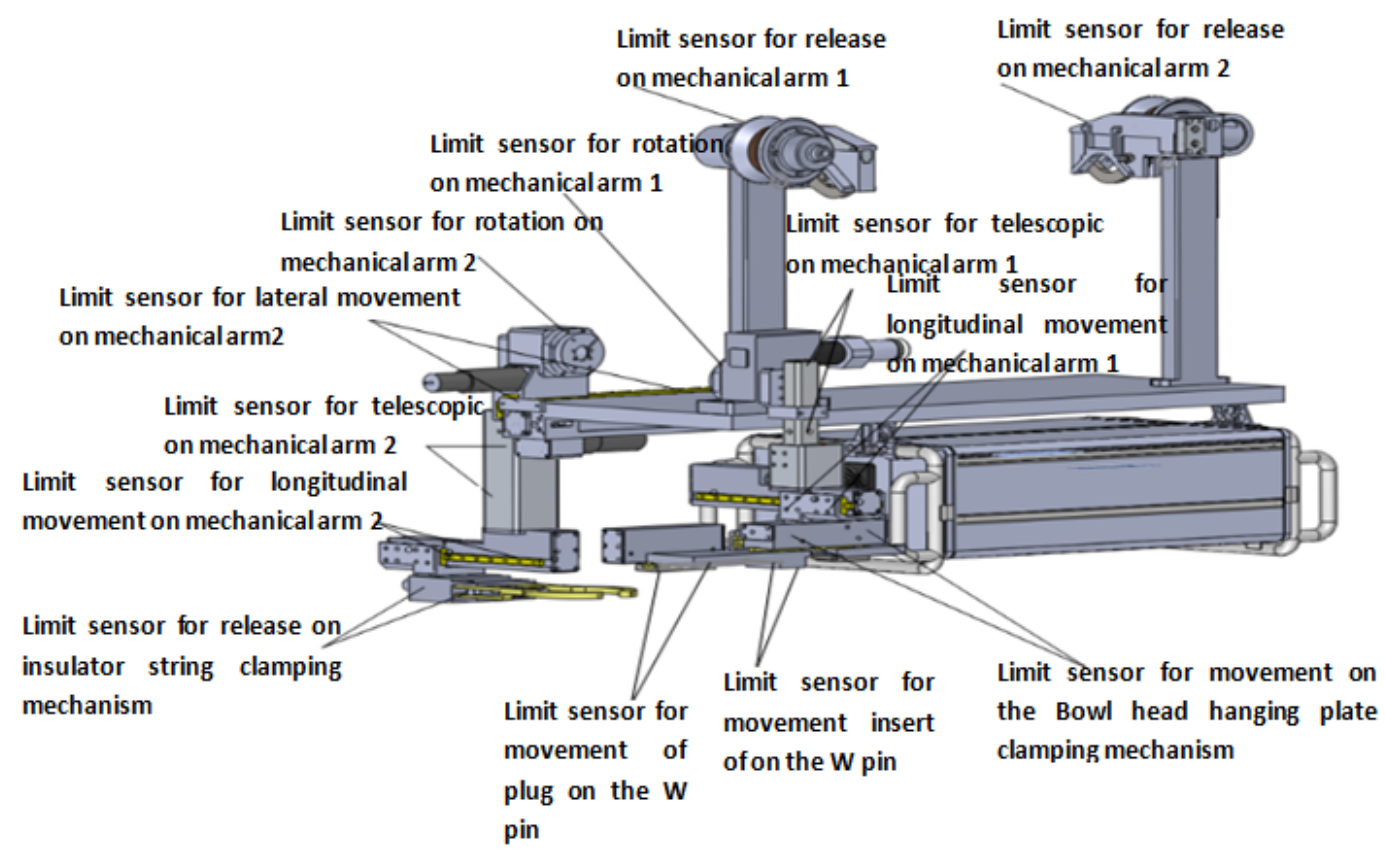

Figure 9. Layout of sensors on live-maintain robot

\subsection{The overall layout of the robot control system}

The Structure of the control box as shown in figure 10 and Layout of electric parts as shown in figure 11. The robot's control box independently suspended on two mechanical arms, the whole control box adopts the frame structure which is made of aluminum alloy and is composed of a cover plate, a panel, a rib and a frame. Strapping Made of stainless steel is installed in Control box at both ends, the strapping possess function of support robot weight, reduce strong electric field interference and easily remove. The design of internal control box adopts module-based structure, including small control box, battery, and fan, switch and so on. The body control system is the core component of the control system which integrated most of the electrical components, including motion controller system, video capture system, communication system, power management system, various types of sensors and external electrical connection interface. The whole layout adopts the structure of the heat-dissipating plate and the supporting frame. The heating elements in the control system are all distributed through the heat-dissipating plate.

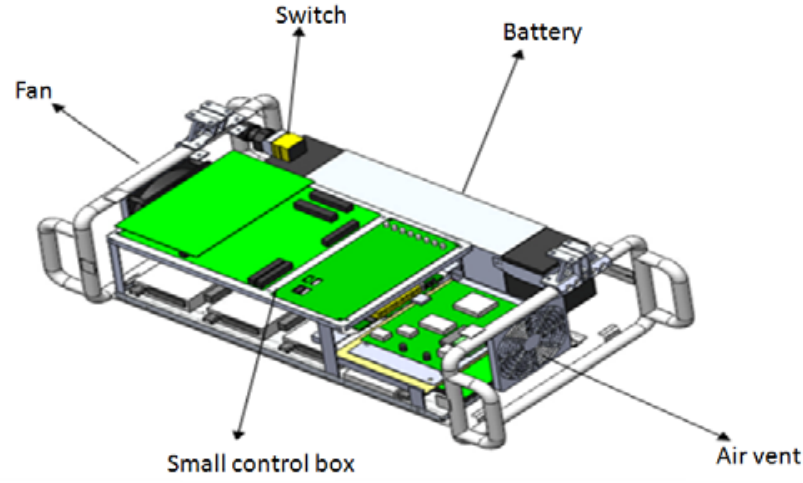

Figure 10. Structure of the control box

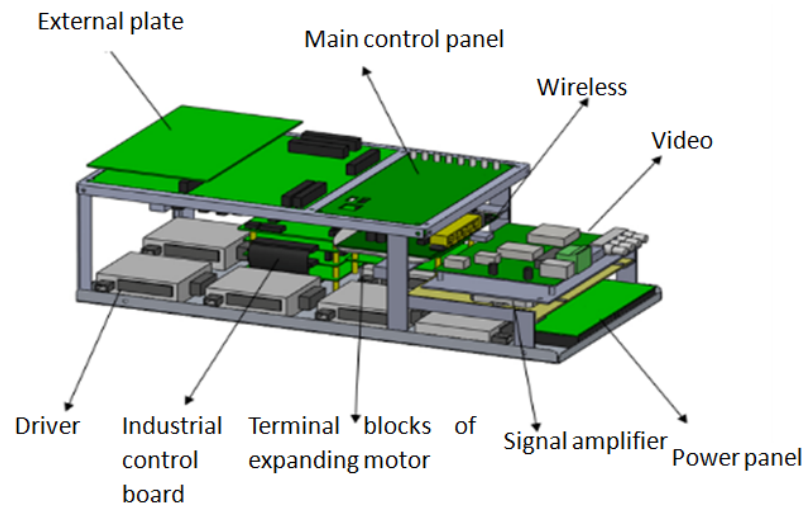

Figure11. Layout of electric parts 


\subsection{Layout of structure of the ground base station}

The ground base station is composed of power supply system, control system and communication system. Among them, the power system is responsible for supply power to the ground station control system, communication systems, monitors and other components; Control system is mainly responsible for monitoring the power supply, receiving, sending, displaying and processing robot information and then make the corresponding control scheme; The communication system mainly includes WIFI communication and WLAN communication, and its function is to realize the long-distance connection with live-maintain robot and provide the channel to transmit related information between the ground base station and the robot .

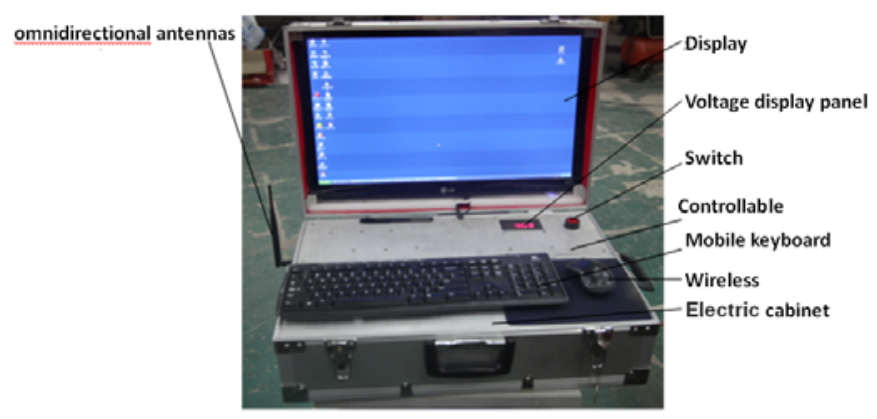

Figure12. The base station system

Control box of ground base station is the local commanding center of robot, all of the control commands are sended out by the ground base station. The physical map of the ground base station is shown in Figure 12, the display using a 23 inch LCD monitor with HD resolution which can display the monitoring image and operation panel at the same time; The control box is composed of a Control cabin and a power cabin, there are industrial control computer, wireless communication device, signal amplifier, power supply system and so on in the Control cabin, The power cabin provide space for storage batteries.

\section{RESEARCH ON PROTOTYPE AND TEST ITS PERFORMANCE}

According to the design ideas we successfully developed the prototype and tested many times in the HV Testing Hall of Wuhan University and the actual transmission lines which is shown in figure 13. Test results show that all the indicators of the robot are normal, the robot can timely receive the control signal from the ground base station, the robot also can independent walking on the wire and help the workers to finish the insulator replacement operation. The ground base station can receive the feedback information of the robot in real time, 4 cameras all work normally, the transfer of video information are clear and smooth. The above results show that the motion control system of live-maintain robot and the base station system are stable, have good ability to resist the inference and high real time work ability which can meet the requirements of practical application.

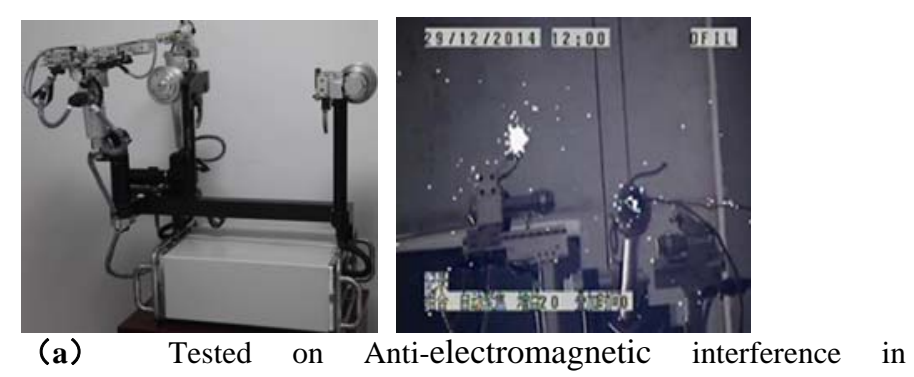
high-voltage hall

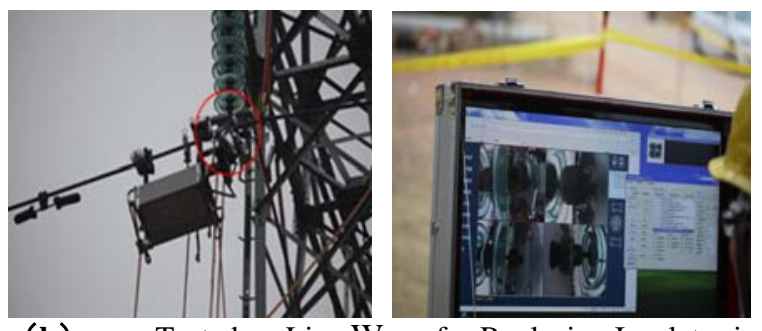

(b) Tested on Live Wore for Replacing Insulator in the site.

Figure13. Text of live-maintain robot

\section{CONCLUSION}

On the foundation of a kinematics modeling based on D-H method, this paper design the control system of live-maintain robot. After several tests, proved that the system has good stability and strong ability to resist the inference. The robot can make the operation personnel to conveniently monitor the running status of the robot body in real time, and can finished some tasks such as replace insulator strings in equal potential. The research not only effectively make Workers avoid directlly touch equipment with high voltage, but also improve the safety of the working people.

\section{REFERENCES}

BAI, Y.C. Research on servo control system of high voltage cable patrolled robot based on DSP[J].Power Electronics, 2005, 39(2): 103-105.

$\mathrm{Hu}, \mathrm{Y}$. Live working technology for transmission line and substation [M]. Beijing, China: China Electric Power Press, 2004. 
Hu, Y. Research and Development of Live Working Technology on Transmission and Distribution Lines[J].High voltage Engineering, 2006, 32(11): 1-10.

LU, S.Y. Research on high voltage electric power live line working robot[J].Automation of Electric Power Systems, 2003, 27(17): 56-58.

Mao, J.G. A distributed control system based on dual-bus frame for power-line-inspection robot[J].Engineering Journal of Wuhan University, 2012, 45(3): 380-384.

Montambault, S. \&Pouliot, N. Design and validation of a mobile robot for power line inspection and maintenance[C]//6th International Conference on Field and Service Robotics-FSR2007, Chamonix, France: Springer, 2008: 495-504.

Pouliot, N. \& Montambault ,S. Geometric design of the linescout, a teleoperated robot for power line inspection and maintenance[C]//Proceedings-7CRA 2008, Pasadena Conference Center, Pasadena, CA, USA, 2008: 3970-3977.

WANG, C.D. Control system design and research of six degree of freedom robot[J].Computer Simulation, 2013, 30(9): 349-353.

XU, X.J. Design and implementation of main control software for inspection robot[J].Engineering Journal of Wuhan University, 2011, 44(5): 671-675.

ZHANG, H.W. CAN-bus-based control system for autonomous underwater vehicle[J]. Robot, 2006, 28(4): 448-452.

Zhang, M.Kinematic modeling and analysis of wrecker manipulator of power line inspection robot[J].Engineering Journal of Wuhan University, 2015, 48(4): 547-550+556.

Zheng, T. Inspection and communication system of robot for high-voltage transmission lines[J].Engineering Journal of Wuhan University, 2012, 45(2): 236-240. 